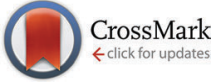

Cite this: Phys. Chem. Chem. Phys., 2017, 19, 6164

Received 24th December 2016, Accepted 27th January 2017

DOI: $10.1039 / \mathrm{c} 6 \mathrm{cp} 08805 \mathrm{~h}$

rsc.li/pccp

\section{Nanosized Pd-Au bimetallic phases on carbon nanotubes for selective phenylacetylene hydrogenation $\dagger$}

\author{
Shenghua Wang, ${ }^{a}$ Zhiling Xin, ${ }^{a}$ Xing Huang, ${ }^{\star b}$ Weizhen $\mathrm{Yu}^{\mathrm{a}}$ Shuo $\mathrm{Niu}^{\mathrm{a}}$ and \\ Lidong Shao*a
}

\begin{abstract}
Palladium (Pd)-catalyzed selective hydrogenation of alkynes has been one of the most studied hydrogenation reactions in the last century. However, kinetic studies conducted to reveal the catalyst's active centers have been hindered because of dynamic surface changes on Pd during the reaction. In the present study, bimetallic $\mathrm{Pd}$-Au nanoparticles supported on carbon nanotubes have been synthesized at room temperature as catalysts for selective hydrogenation of phenylacetylene, which show effectively enhanced selectivity compared to their monometallic counterparts. Structural and surface analyses of fresh and reacted catalysts reveal that selective hydrogenation of phenylacetylene is favored over nanosized $\mathrm{Pd}-\mathrm{Au}$ bimetallic phases due to modifications in the Pd surface in terms of neighboring site isolation and electron density reduction.
\end{abstract}

\section{Introduction}

In the polymerization industry, alkyne removal from alkenes by selective hydrogenation is a process of great significance, because alkyne impurities in alkenes poison polymerization catalysts, leading to product deterioration., ${ }^{1,2}$ Palladium (Pd)-based catalysts, being the most applicable catalysts in alkyne-selective hydrogenation, have been discussed for decades., ${ }^{3,4}$ Owing to the strong affinity of palladium towards $\mathrm{H}_{2}$, full hydrogenation of alkynes to alkanes often takes place on monometallic Pd catalysts. ${ }^{5}$ In addition, Pd-based catalysts suffer fast deactivation and selectivity reduction because of the generated and accumulated carbonaceous deposits on Pd and its support surfaces. ${ }^{6-8}$ On the other hand, alkyne-selective hydrogenation has been researched using supported Au nanoparticles as catalyst materials in the last decade, as Au alone is regarded as a poor catalyst in alkyne selective hydrogenation. ${ }^{9,10}$ Although the catalytic activity of $\mathrm{Au}$ nanoparticles was still inferior to those of other noble metals, Au nanoparticles showed improved selectivities on various supporting materials. ${ }^{11,12}$

In recent decades, bimetallic catalysts have attracted considerable attention because the mixtures often exhibit enhanced catalytic activities, stabilities, or selectivities due to the presence

\footnotetext{
${ }^{a}$ Shanghai Key Laboratory of Materials Protection and Advanced Materials in Electric Power, Shanghai University of Electric Power, 2103 Pingliang Road, Shanghai 200090, China. E-mail: lidong.shao@shiep.edu.cn

${ }^{b}$ Department of Inorganic Chemistry, Fritz-Haber Institute of the Max Planck Society, Faradayweg 4-6, 14195 Berlin, Germany. E-mail: xinghuang@fhi-berlin.mpg.de $\dagger$ Electronic supplementary information (ESI) available: Details of the catalyst preparation, catalyst characterization and catalytic tests. See DOI: 10.1039/c6cp08805h
}

of the second metal component. ${ }^{13}$ Among the bimetallic catalysts, the complete miscibility, small amount of lattice mismatch, and vastly different catalytic properties of $\mathrm{Pd}$ and $\mathrm{Au}$ make $\mathrm{Pd}-\mathrm{Au}$ a unique system for study. $\mathrm{Pd}-\mathrm{Au}$ bimetallic nanoparticles are technically important for vinyl acetate synthesis. ${ }^{14}$ They also have great potential as catalysts for other industrial processes such as direct $\mathrm{H}_{2} \mathrm{O}_{2}$ synthesis. ${ }^{15}$ However, applying the bimetallic $\mathrm{Pd}-\mathrm{Au}$ nanoparticles as catalysts for alkyne selective hydrogenation has rarely been reported. The role of the catalytic modification of $\mathrm{Pd}$ by $\mathrm{Au}$ in influencing alkyne hydrogenation remains unclear. Moreover, from the Pd-Au catalyst synthesis point of view, simple and environmentally friendly methods are needed for realizing scaled-up conversion under technically relevant conditions.

In the present work, $\mathrm{Pd}-\mathrm{Au} /$ carbon nanotube $(\mathrm{CNT})$ catalysts have been prepared by liquid phase reduction at room temperature, free of additives and byproducts, and phenylacetylene hydrogenations have been carried out over Pd-Au/CNTs and reference catalysts $\mathrm{Pd} / \mathrm{CNTs}$ and $\mathrm{Au} / \mathrm{CNTs}$ at $40{ }^{\circ} \mathrm{C}$. Details of the experimental procedures including catalyst preparation, catalyst characterization and catalytic tests are given in the ESI. $\dagger$ Structural and surface analyses were conducted on the fresh and reacted catalysts to investigate the role of the catalytic modification of Pd by $\mathrm{Au}$ in affecting the selective hydrogenation pathways.

\section{Results and discussion}

To ensure the complete reduction of Pd and Au on CNTs, the actual catalyst loadings were measured by inductively coupled plasma optical emission spectrometry (ICP-OES; Table S1, ESI $\dagger$ ). 
It shows that metal loadings of the prepared Pd/CNTs and $\mathrm{Pd}-\mathrm{Au} / \mathrm{CNTs}$ are consistent with the values calculated from the added salt ratios. However, for the prepared Au/CNT catalysts, significant differences between the observed and the theoretical values were observed. The results obtained from the ICP-OES measurements indicated that the interaction between the precursor solution of Au particles and the CNT support was poor. This is in line with the research of Jiang Kuiyang, ${ }^{16}$ in which he found almost no Au nanoparticles on the nanotubes when acidtreated CNTs were mixed with Au colloids. To ensure that the $\mathrm{Au} / \mathrm{CNT}$ reference catalyst has a relatively equal amount of $\mathrm{Au}$ in comparison to the Pd-Au/CNTs, a new Au/CNTs catalyst was prepared by using the same liquid-phase reduction method, but without the filtration step. The metal loading of the newly prepared Au/CNTs was 8.01 wt\% by ICP-OES.

Fig. 1(a) shows a scanning transmission electron microscopy (STEM) image of dispersed Pd-Au bimetallic nanoparticles on the CNTs. Fig. 1(b) shows a high-resolution scanning transmission electron microscopy (HR-STEM) image of the bimetallic nanoparticle at a higher magnification. The elemental maps and STEM-energydispersive X-ray (EDX) analyses of the bimetallic nanoparticles in Fig. 1(c) are shown in Fig. 1(d and e). Pd and Au appear homogeneously distributed within the nanoparticles, revealing the alloying state of the nanoscale catalysts. Furthermore, based on the HRSTEM image, the interplanar distances were accurately measured as $0.230 \mathrm{~nm}$. Considering that the lattice parameters of fcc Pd and $\mathrm{Au}$ metals are $0.226 \mathrm{~nm}$ and $0.235 \mathrm{~nm}$, respectively, an interplanar distance of $0.230 \mathrm{~nm}$ indicates good miscibility between $\mathrm{Pd}$ and $\mathrm{Au}$ in the formed bimetallic alloys. The morphologies of Pd/CNTs and $\mathrm{Au} / \mathrm{CNTs}$ are shown in Fig. S1 and S2 (ESI $\dagger$ ), respectively.

Fig. 2 shows the plots of the catalytic performance of $\mathrm{Pd}-\mathrm{Au} /$ $\mathrm{CNTs}, \mathrm{Pd} / \mathrm{CNTs}$ and $\mathrm{Au} / \mathrm{CNTs}$ under the same reaction conditions.
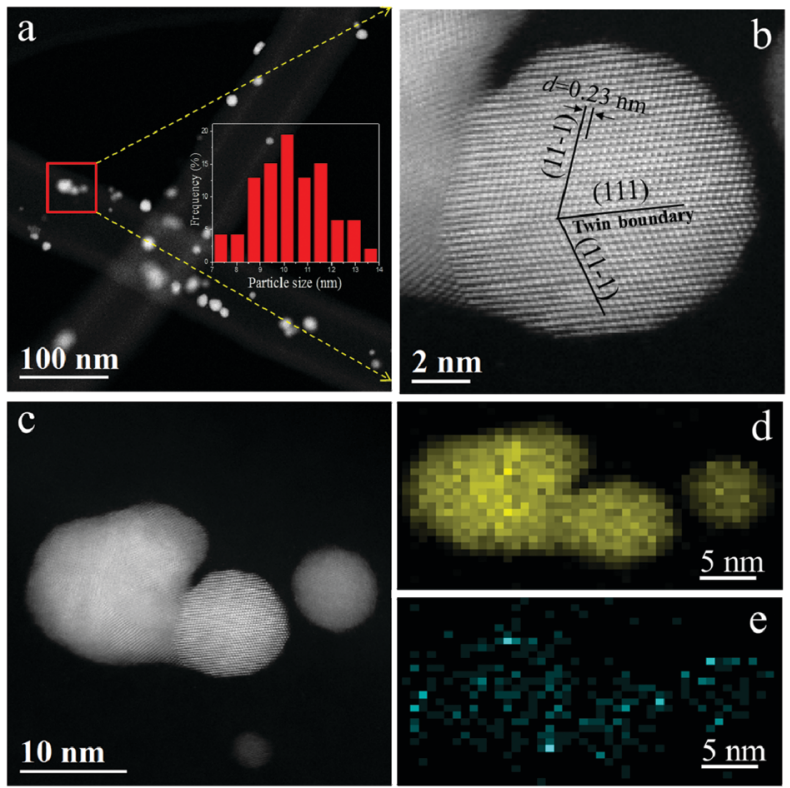

Fig. 1 (a) STEM image of Pd-Au/CNTs, inset shows the Pd-Au size distribution. (b) HR-STEM image of a Pd-Au bimetallic nanoparticle. (c-e) STEM-EDX maps of $\mathrm{Pd}-\mathrm{Au}$ bimetallic nanoparticles.
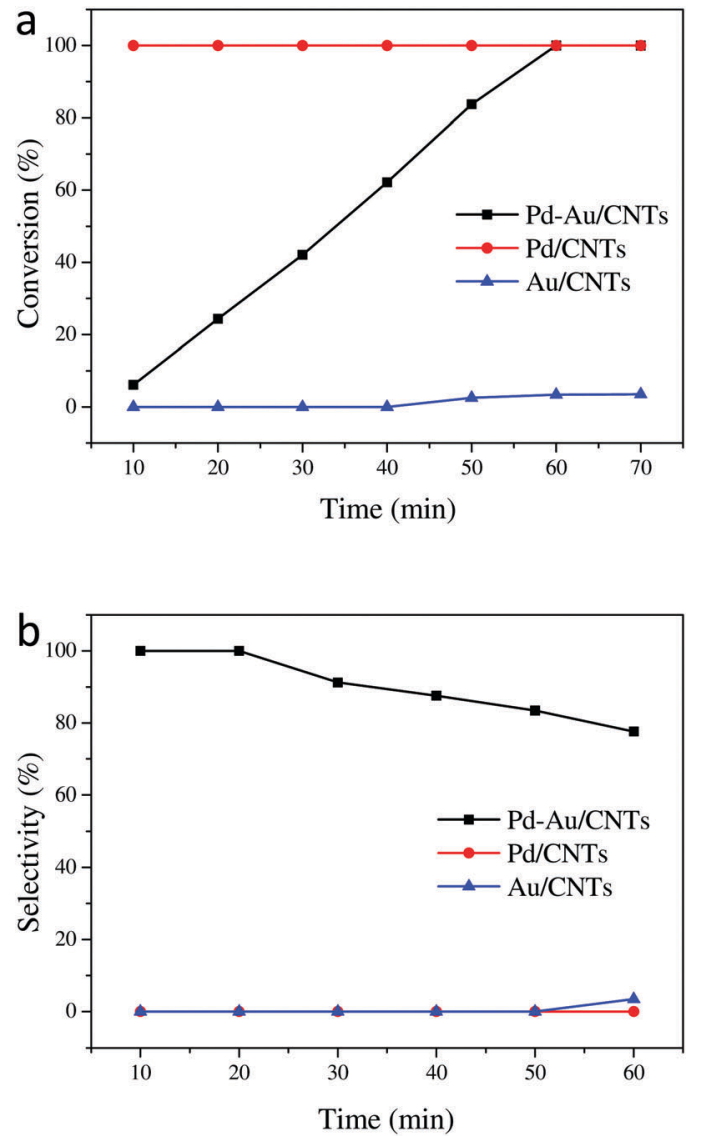

Fig. 2 The catalytic performances of the Pd/CNT, Au/CNT, and Pd-Au/CNT catalysts for phenylacetylene selective hydrogenation at $40^{\circ} \mathrm{C}$ : (a) conversion of phenylacetylene and (b) selectivity to styrene.

For the Pd/CNT catalyst, we can see that a complete hydrogenation was achieved under the applied conditions. For the Au/CNT catalyst, the reaction was almost negligible under the applied conditions, as shown in Fig. 2. For the Pd-Au/CNT catalyst, the reaction took place steadily until conversion, and selectivity towards styrene slowly decreased. In order to prove the improved selectivity toward styrene over $\mathrm{Pd}-\mathrm{Au} / \mathrm{CNTs}$, the profile of selectivity versus conversion in phenylacetylene hydrogenation over $\mathrm{Pd}-\mathrm{Au} / \mathrm{CNTs}$ is added in Fig. S3 (ESI $\dagger$ ). When compared to the monometallic catalysts, the bimetallic catalyst Pd-Au/CNTs showed much improved catalytic performances. The kinetic model and reaction mechanism for phenylacetylene hydrogenation have been discussed previously. ${ }^{17,18}$ It has been reported that hydrogenation of phenylacetylene to the corresponding styrene and ethylbenzene proceeds by a two-pathway mechanism. One pathway involves the direct hydrogenation of the triple bond to a single bond, and the other involves a two-step hydrogenation including the formation of a single or multiple adsorbed species. To investigate the structural stability of the applied catalysts under the reaction conditions, X-ray diffraction (XRD) was applied to the fresh and reacted catalysts (reaction conducted at $40{ }^{\circ} \mathrm{C}$ for 60 minutes). The average size of the nanoparticles estimated using Scherrer's equation for the $\mathrm{Pd}-\mathrm{Au} / \mathrm{CNTs}, \mathrm{Pd} / \mathrm{CNTs}$ and $\mathrm{Au} / \mathrm{CNTs}$ was calculated to be $9.8 \pm 0.2 \mathrm{~nm}, 9.0 \pm 0.2 \mathrm{~nm}$ and $10.4 \pm 0.2 \mathrm{~nm}$, respectively. 


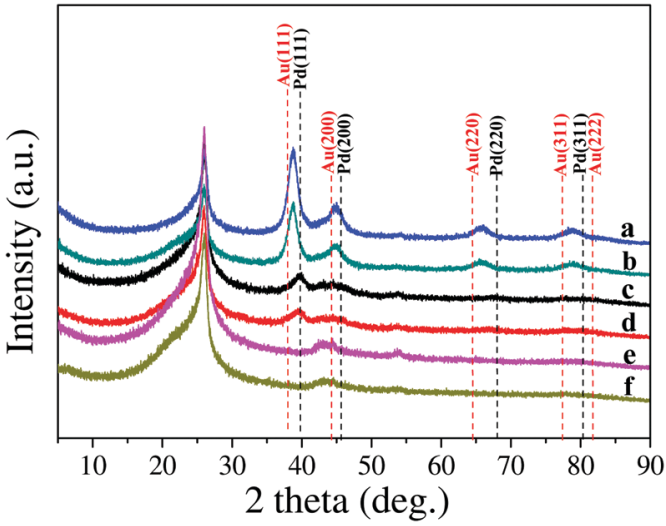

Fig. 3 XRD patterns of the (a) Pd-Au/CNT catalyst before reaction, (b) Pd-Au/CNT catalyst after reaction, (c) Pd/CNT catalyst before reaction, (d) Pd/CNT catalyst after reaction, (e) Au/CNT catalyst before reaction, and (f) Au/CNT catalyst after reaction.

A strong diffraction peak at $26.1^{\circ}$, corresponding to the hexagonal graphite (002) plane of the CNT support, indicated that the CNT support has a high degree of graphite structure. ${ }^{19}$ The presence of Pd with a face-centered cubic (fcc) structure can be inferred from the diffraction peaks at $39.8^{\circ}\left((111)\right.$ plane) and $46.4^{\circ}$ ((200) plane). The diffraction pattern of Au/CNTs is not intensive to assign peaks; however, the diffraction pattern of the bimetallic Pd-Au/CNTs (Fig. 3(a)) exhibited clear shifts of the Pd diffraction peaks, indicating that partially covalent bonds were formed within the $\mathrm{Pd}-\mathrm{Au} / \mathrm{CNT}$ alloys. Fig. 3(b) also shows the XRD pattern of the reacted catalyst; no visible changes were observed on $\mathrm{Pd}-\mathrm{Au} / \mathrm{CNTs}$, indicating that the applied catalyst was relatively thermally stable under the reaction conditions.

Raman spectroscopy was applied to evaluate the graphitic structures of the fresh and reacted catalysts. The Raman spectra of the $\mathrm{Pd}-\mathrm{Au} / \mathrm{CNT}, \mathrm{Pd} / \mathrm{CNT}$, and Au/CNT catalysts are shown in Fig. 4. The $I_{\mathrm{D}} / I_{\mathrm{G}}$ values of the three catalysts before reaction are $0.91,0.87$, and 0.91 , respectively, while those after reaction are $0.92,0.86$, and 0.90. Raman characterization shows that there have been no obvious structural changes on CNT supports during the hydrogenation reactions. It means that the byproducts generated during the reaction are not adsorbed on the support surface obviously.

The significant differences in reactivity prompted a detailed analysis of the surface properties of the applied catalysts. The surface and near-surface properties of both fresh and reacted catalysts were characterized using X-ray photoelectron spectroscopy (XPS). Fig. 5(a) shows the fitted Pd 3d core-level XPS spectra of the fresh and reacted Pd/CNTs and Pd-Au/CNTs. The $\mathrm{Pd} 3 \mathrm{~d}(5 / 2)$ peak at $335.8 \mathrm{eV}$ for the $\mathrm{Pd} / \mathrm{CNTs}$ has been reportedly assigned to the monometallic Pd nanoparticles. ${ }^{20}$ As the size of the particles decreases the Pd $3 \mathrm{~d}$ peak undergoes a positive binding energy (BE) shift. Upon addition of Au, the original Pd peak profile is gradually weakened, and a new Pd feature emerges at lower binding energies. This could be a result of strong interaction between $\mathrm{Au}$ and $\mathrm{Pd}$ as observed in Pd-Au alloys. ${ }^{21}$ The presently observed charge redistribution in Pd-Au NPs is caused by Pd losing $\mathrm{s}$, p-electrons and gaining d-electrons with net electron loss, while Au gains net d-electrons. ${ }^{21,22}$

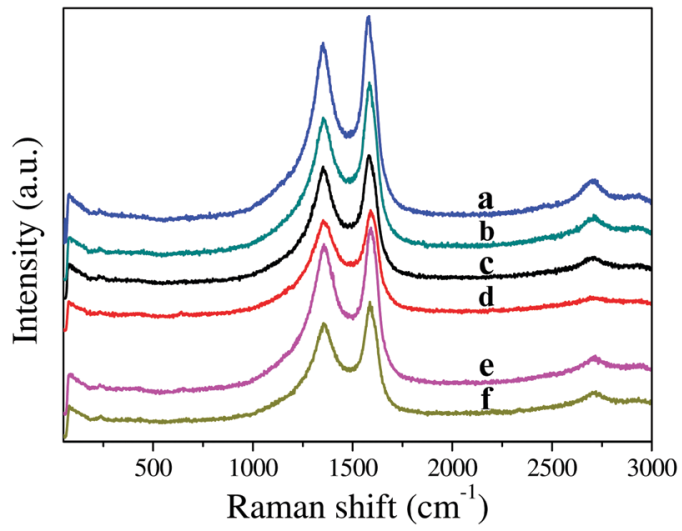

Fig. 4 Raman spectra of the (a) Pd-Au/CNT catalyst before reaction, (b) $\mathrm{Pd}-\mathrm{Au} / \mathrm{CNT}$ catalyst after reaction, (c) Pd/CNT catalyst before reaction, (d) $\mathrm{Pd} / \mathrm{CNT}$ catalyst after reaction, (e) Au/CNT catalyst before reaction, and (f) $\mathrm{Au} / \mathrm{CNT}$ catalyst after reaction.
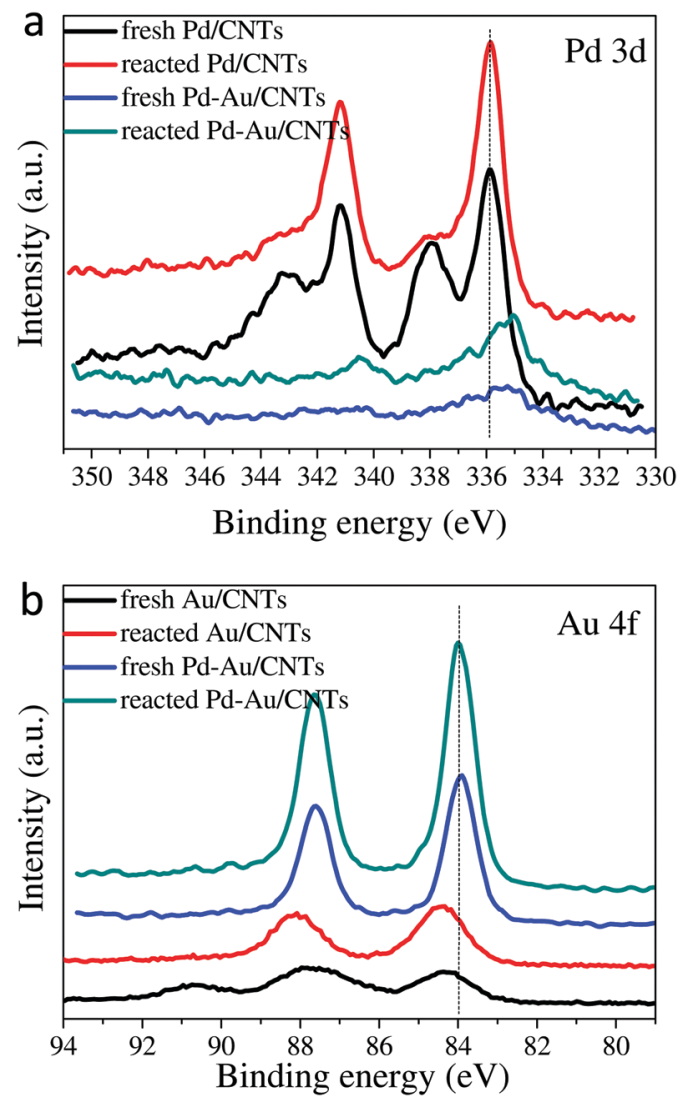

Fig. 5 XPS spectra of (a) Pd 3d for the fresh and reacted Pd/CNTs and $\mathrm{Pd}-\mathrm{Au} / \mathrm{CNTs}$. (b) Au $4 \mathrm{f}$ for the fresh and reacted Au/CNTs and Pd-Au/CNTs.

Fig. $5 \mathrm{~b}$ shows the fitted $\mathrm{Au} 4 \mathrm{f}$ core-level XPS spectra of the fresh and reacted $\mathrm{Au} / \mathrm{CNTs}$ and $\mathrm{Pd}-\mathrm{Au} / \mathrm{CNTs}$. It can be seen that the binding energy (BE) of the Au $4 \mathrm{f}$ peak for the fresh Au/CNTs is $\sim 84.0 \mathrm{eV}$. Compared to the Au monometallic phases on fresh $\mathrm{Au} / \mathrm{CNTs}$, the $\mathrm{Au} 4 \mathrm{f}$ peak is shifted to lower binding energies for $\mathrm{Pd}-\mathrm{Au}$ bimetallic NPs on CNTs. This is due to electron transfer from $\mathrm{Pd}$ to $\mathrm{Au}$, which is in accordance with previous reports in the Au XPS literature. ${ }^{22}$ 


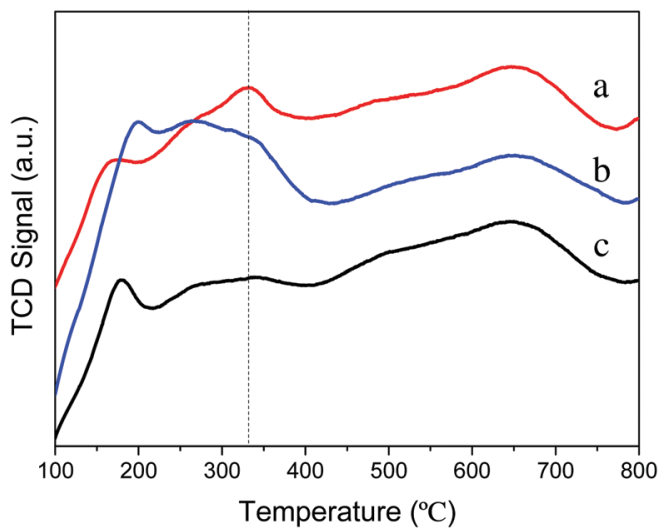

Fig. $6 \mathrm{H}_{2}$-TPD profiles of Pd/CNTs (a), Au/CNTs (b) and Pd-Au/CNTs (c).

Fig. 5 also shows the XPS profiles for the reacted Pd/CNT, $\mathrm{Au} / \mathrm{CNT}$, and $\mathrm{Pd}-\mathrm{Au} / \mathrm{CNT}$ catalysts. The distribution of Pd species remained similar, indicating that $\mathrm{Pd}$ is reasonably stable. However, in the case of Pd/CNTs and Au/CNTs, the reaction clearly affected the Pd $3 \mathrm{~d}$ and $\mathrm{Au} 4 \mathrm{f}$ profiles in terms of intensity ratios and peak positions, suggesting the occurrence of dynamic changes on the monometallic surfaces during the selective hydrogenation, while in the $\mathrm{Pd}-\mathrm{Au} / \mathrm{CNT}$ catalyst, relatively stable $\mathrm{Pd}$ and $\mathrm{Au}$ surfaces were preserved under the same reaction conditions.

In this work, temperature-programmed desorption of $\mathrm{H}_{2}$ $\left(\mathrm{H}_{2}-\mathrm{TPD}\right)$ was employed to investigate the correlation between the active sites and hydrogenation performances from the view of $\mathrm{H}_{2}$ interaction. Thermal desorption curves of hydrogen from the catalysts are displayed in Fig. 6. The profile of Pd/CNTs exhibited a peak at $332{ }^{\circ} \mathrm{C}$, whereas there was no peak for $\mathrm{Au} / \mathrm{CNTs}$ and $\mathrm{Pd}-\mathrm{Au} / \mathrm{CNTs}$. The $\mathrm{H}_{2}$ TPD pattern reveals the various interactions between the adsorbed $\mathrm{H}_{2}$ species and the metal particles. ${ }^{23}$ As a result, this was reflected by their reactions: $\mathrm{Au} / \mathrm{CNTs}$ showed sluggish reactivity towards phenylacetylene hydrogenation being inert towards $\mathrm{H}_{2}$, whereas for monometallic Pd catalysts, complete hydrogenation of phenylacetylene took place over Pd/CNTs due to the strong affinity of palladium towards $\mathrm{H}_{2}$ in the current study. Therefore, adding Au to Pd suppresses $\mathrm{H}_{2}$ adsorption, as observed in Fig. 6 .

In the current study, the surface functionalities on the CNTs produce an anchoring effect towards salt precursors. Functional groups coordinated with the metal ions were hydrolyzed to crystallize the precursors nucleated on the oxidized carbon supports and to generate nanocrystals. ${ }^{24,25}$ During synthesis, the aggregation of the reduced Pd and Au precursors via Ostwald ripening was hindered by interactions between the metal species and the surface functionalities of the CNTs. In this study, Pd-Au bimetallic phases may have formed in the Pd-Au NPs during the reduction treatments because of the strong driving force for the dissolution of Au in Pd. Meanwhile, after dissolving in Pd, Au appears to have isolated Pd neighboring atoms on the surface and sub-surface regions of Pd-Au alloy NPs.

Subsurface chemistry governs the catalytic properties of Pd-based catalysts in selective hydrogenation applications. ${ }^{7}$
Pd-hydride $\left(\mathrm{PdH}_{x}\right)$, Pd-carbide $\left(\mathrm{PdC}_{y}\right)$, or coexisting phases of composition $\mathrm{PdH}_{x} \mathrm{C}_{y}$ may influence catalysis by modifying and generating additional active phases under reaction conditions. ${ }^{8}$ For monometallic Pd catalysts used in the current study, complete hydrogenation of phenylacetylene took place due to the strong affinity of palladium towards $\mathrm{H}_{2}$. For the supported $\mathrm{Pd}-\mathrm{Au}$ bimetallic NPs in the present study, the absence of less surface and subsurface dynamics indicated weaker interactions between $\mathrm{Pd}-\mathrm{Au} / \mathrm{CNTs}$ and $\mathrm{H}_{2}$ and suggested preferential adsorption toward the alkyne triple bonds $(\mathrm{C} \equiv \mathrm{Cs})$. Thus, the enhanced preference for adsorbing phenylacetylene and desorbing styrene explains the improved selectivity toward styrene over supported Pd-Au bimetallic NPs.

\section{Conclusions}

In this study, supported bimetallic Pd-Au NPs were synthesized at room temperature as catalysts for selective hydrogenation of phenylacetylene with enhanced selectivities compared to their monometallic counterparts. The enhanced selectivities obtained over Pd-Au/CNTs are explained by the hindered surface dynamics of the nanoscale bimetallic phases under a reactive atmosphere and the preference for desorption of partial hydrogenation products. Isolation of neighboring Pd atoms accomplished by adding $\mathrm{Au}$ could be responsible for the generation of specific active surface sites that are selective for controlled hydrogenation of phenylacetylene. Moreover, the charge redistribution in $\mathrm{Pd}-\mathrm{Au}$ NPs can induce weaker interaction between surface modified $\mathrm{Pd}$ and $\mathrm{H}_{2}$ and preferential adsorption toward the alkyne triple bonds $(\mathrm{C} \equiv \mathrm{Cs})$.

\section{Acknowledgements}

This work was supported by the National Natural Science Foundation of China (21403137). Open Access funding is provided by the Max Planck Society.

\section{Notes and references}

1 M. Crespoquesada, F. Cárdenaslizana, A. L. Dessimoz and L. Kiwiminsker, ACS Catal., 2012, 2, 1773-1786.

2 E. Karakhanov, A. Maximov, Y. Kardasheva, V. Semernina, A. Zolotukhina, A. Ivanov, G. Abbott, E. Rosenberg and V. Vinokurov, ACS Appl. Mater. Interfaces, 2014, 6, S54.

3 D. Teschner, E. Vass, M. Hävecker, S. Zafeiratos, P. Schnörch, H. Sauer, A. Knop-Gericke, R. Schlögl, M. Chamam, A. Wootsch, A. Canning, J. Gamman, D. Jackson, J. McGregor and L. Gladden, J. Catal., 2006, 242, 26-37.

4 K. Y. Han, H. R. Zuo, Z. W. Zhu, G. P. Cao, C. Lu and Y. H. Wang, Ind. Eng. Chem. Res., 2013, 52, 3783-3788.

5 Y. Gao, C. A. Chen, H. M. Gau, J. A. Bailey, E. Akhadov, D. Williams and W. Hsing-Lin, Chem. Mater., 2008, 20, 2839-2844.

6 D. Mei, M. Neurock and C. M. Smith, J. Catal., 2009, 268, 181-195. 
7 D. Teschner, Z. Révay, J. Borsodi, M. Hävecker, A. KnopGericke, R. Schlögl, D. Milroy, S. D. Jackson, D. Torres and P. Sautet, Angew. Chem., Int. Ed., 2008, 47, 9274-9278.

8 D. Teschner, J. Borsodi, A. Wootsch, Z. Révay, M. Hävecker, A. Knop-Gericke, S. D. Jackson and R. Schlögl, Science, 2008, 320, 86-89.

9 S. Galvagno and G. Parravano, J. Catal., 1979, 57, 272-286.

10 V. I. Pârvulescu, P. Viorica, E. Uwe, F. George, F. E. Wagner, K. Christian and R. Ryan, Chem. - Eur. J., 2006, 12, 2343-2357.

11 L. D. Shao, X. Huang, D. Teschner and W. Zhang, ACS Catal., 2014, 4, 2369-2373.

12 M. Boronat and A. Corma, Langmuir, 2010, 26, 16607-16614.

13 C. Li, Z. Shao, M. Pang, C. T. Williams, X. Zhang and C. Liang, Ind. Eng. Chem. Res., 2012, 51, 4934-4941.

14 Y. F. Han, J. H. Wang, D. Kumar, Z. Yan and D. W. Goodman, J. Catal., 2005, 232, 467.

15 J. K. Edwards, E. Ntainjua, A. F. Carley, A. A. Herzing, C. J. Kiely and G. J. Hutchings, Angew. Chem., Int. Ed., 2009, 48, 8512.

16 K. Jiang, A. Eitan, L. S. Schadler, P. M. Ajayan and R. W. Siegel, Nano Lett., 2003, 3, 275-277.
17 B. A. Wilhite, M. J. McCready and A. Varma, Ind. Eng. Chem. Res., 2002, 41, 3345-3350.

18 X. Chen, A. Zhao, Z. Shao, C. Li, C. T. Williams and C. Liang, J. Phys. Chem. C, 2010, 114, 16525-16533.

19 O. Winjobi, Z. Zhang, C. Liang and W. Li, Electrochim. Acta, 2010, 55, 4217-4221.

20 G. K. Wertheim, S. B. DiCenzo and D. E. Buchanan, Phys. Rev. B: Condens. Matter Mater. Phys., 1986, 33, 5384-5390.

21 J. Xu, T. White, P. Li, C. He, J. Yu, W. Yuan and Y. F. Han, J. Am. Chem. Soc., 2010, 132, 10398-10406.

22 T. Balcha, J. R. Strobl, C. Fowler, P. Dash and R. W. J. Scott, ACS Catal., 2011, 1, 425-436.

23 T. Chen, D. Li, J. Hong and C. Xiong, Chem. Eng. J., 2015, 259, 161-169.

24 R. N. D’Alnoncourt, M. Friedrich, E. Kunkes, D. Rosenthal, F. Girgsdies, B. S. Zhang, L. D. Shao, M. Schuster, M. Behrens and R. Schlögl, J. Catal., 2014, 317, 220-228.

25 L. D. Shao, T. W. Lin, G. Tobias and M. L. Green, Chem. Commun., 2008, 2164-2166. 